\title{
Acute Lung Injury: Disease Modelling and the Therapeutic Potential of Stem Cells
}

\author{
Jie Lian, Juntang Lin, Norashikin Zakaria, \\ and Badrul Hisham Yahaya
}

\section{Abstract}

Acute lung injury (ALI) is a severe clinical condition with high morbidity and mortality that usually results in the development of multiple organ dysfunction. The complex pathophysiology of ALI seems to provide a wide range of targets that offer numerous therapeutic options. However, despite extensive studies of ALI pathophysiology and treatment, no effective pharmacotherapy is available. Increasing evidence from both preclinical and clinical studies supports the preventive and therapeutic effects of mesenchymal stem cells (MSCs) for treating ALI. As cell-based therapy poses the risk of occlusion in microvasculature or

\section{J. Lian}

Lung Stem Cell and Gene Therapy Group, Regenerative Medicine Cluster, Advanced Medical and Dental Institute (IPPT), Universiti Sains Malaysia, SAINS@Bertam, Penang, Malaysia

Stem Cell and Biotherapy Technology Research Center of Henan Province, College of Life Science and Technology, Xinxiang Medical University, Xinxiang, Henan, China

J. Lin

Stem Cell and Biotherapy Technology Research Center of Henan Province, College of Life Science and Technology, Xinxiang Medical University, Xinxiang, Henan, China

N. Zakaria and B. H. Yahaya $(\bowtie)$

Lung Stem Cell and Gene Therapy Group, Regenerative Medicine Cluster, Advanced Medical and Dental Institute (IPPT), Universiti Sains Malaysia, SAINS@Bertam,

Penang, Malaysia

e-mail: badrul@usm.my unregulated growth, MSC-derived extracellular vesicles (MSC-EVs) have been extensively studied as a new therapeutic strategy for non-cell based therapy. It is widely accepted that the therapeutic properties of MSCs are derived from soluble factors with paracrine or endocrine effects, and EVs are among the most important paracrine or endocrine vehicles that can deliver various soluble factors with a similar phenotype as the parent cell. Therapeutic effects of MSCs have been reported for various delivery approaches, diverse doses, multiple origins, and different times of administration, and MSC-EVs treatment may include but is not limited to these choices. The mechanisms by which MSCs and MSC-EVs may contribute to ALI treatment remain elusive and need further exploration. This review provides an overview of preclinical studies that support the application of MSC-EVs for treating ALI, and it discusses emerging opportunities and their associated challenges.

\section{Keywords}

Acute lung injury $\cdot$ Animal model $\cdot$ Cell-free therapy · Extracellular vesicles · Intratracheal delivery $\cdot$ Mesenchymal stem cells . Pathophysiology 


\section{Abbreviations}

AEC I Type I alveolar epithelial cells

AEC II Type II alveolar epithelial cells

ALI Acute lung injury

$\operatorname{Am} \varphi \quad$ Alveolar macrophages

ARDS Acute respiratory distress syndrome

ATS American thoracic society

BALF Broncho-alveolar lavage fluid

DMSO Dimethyl sulphoxide

EBD Evans blue dye

ELISA Enzyme-linked immunosorbent assay

ESCRT Endosomal sorting complex required for transport

H\&E Hematoxylin and Eosin

hAD- Human adipose-derived MSCs

MSCs

hBM-

MSCs

HLA

hMens-

MSCs

hUC-

MSCs

i.t.

i.v.

LPS

MFGE8

MHC

MISEV

MPO

MSC-EVs

MSCs

PARDS

PDCD61P Programmed cell death 6 interacting protein

PMN Polymorphonuclear

qRT-PCR Qualitative reverse transcriptase polymerase chain reaction

TSG101 Tumor susceptibility gene 101 protein

TSPAN29 Tetraspanin 29

VILI Ventilator-induced lung injury

\section{Introduction}

\subsection{Acute Lung Injury}

Acute lung injury (ALI) or its clinical manifestation, acute respiratory distress syndrome (ARDS), is an acute inflammatory lung injury that usually is responsible for high morbidity and mortality as well as the development of multiple organ dysfunction. ARDS was first proposed in 1967 (Ashbaugh et al. 1967); "A" originally was the abbreviation for adult, but it was later changed to acute. As our understanding of the condition grew, the definition changed from the American-European Consensus Conference Committee definition (Bernard et al. 1994) to the Berlin definition (Force et al. 2012; Ferguson et al. 2012). The latter classifies the severity of the condition from mild to severe. In addition, the pediatric ARDS (PARDS) definition was developed by the Pediatric Acute Lung Injury Consensus Conference in 2015 (Pediatric Acute Lung Injury Consensus Conference Group 2015). Although tremendous progress has been made both in therapy and nursing over the last half century, ALI is still a significant source of morbidity, mortality, and financial burden.

Over three million patients suffer from ARDS every year, and they constitute more than $10 \%$ of patients of intensive care units. Moreover, ARDS is likely to be underreported in low-income countries, as it is under-recognized even in highincome countries (Thompson et al. 2017; Villar et al. 2016). Bellani et al. (2016) studied 29,144 patients from 459 intensive care units in 50 countries across 5 continents and found that clinical recognition rates ranged from $51.3 \%$ for mild ARDS to $78.5 \%$ for severe ARDS, and the condition appeared to be a public health problem globally, with a very high mortality of approximately $40 \%$. Even patients who survive from ALI are at high risk for long-term poor quality of life (Herridge et al. 2016; Biehl et al. 2015). Children are no exception, as another international study that involved 23,280 patients from 145 pediatric intensive care units in 27 countries found that PARDS occurs in approximately $3 \%$ of patients 
but results in $\sim 17 \%$ mortality (Khemani et al. 2019).

To date, there has been no comprehensive epidemiology study of ARDS in China, but the incidence, mortality, and risk factors for ARDS and PARDS in China are thought to be similar to those in Europe and the United States based on several relatively regional studies, which suggest that the annual number of cases in China is more than 670,000 patients (Song et al. 2014). However, health emergency related ALI is not included. During twenty-first century, there are three outbreaks of coronavirus infection around the world, including SARS (Severe Acute Respiratory Syndrome) in 2002, 10 years later with MERS (Middle East Respiratory Syndrome) in 2012 and more recently from December 2019 with COVID19 (Corona Virus Disease). So far, there is no principle to follow for the therapy of COVID19 especially for severe patients because of absence of efficacious drugs and vaccines for SARS and MERS until now. Under the support of WHO (World Health Organization), several specific treatments were under investigation and would be tested through clinical trials, and cell therapy was included.

ALI is a public health problem and common complication in critically ill patient groups, with significantly high mortality and poor outcome. No effective pharmacotherapy exists, so it is necessary to further investigate its pathophysiology and try to find more effective treatments. The goals of this review are to summarize evidence from preclinical studies that supports more efficient therapy for ALI and to discuss emerging opportunities and their associated challenges. The use of mesenchymal stem cells (MSCs) has the potential to treat a variety of diseases, and MSC-derived extracellular vesicles (MSC-EVs) could be a future novel treatment strategy for pulmonary inflammatory disease via intratracheal delivery.

\subsection{Pathogenesis of ALI}

ALI originates from multiple factors, including direct and indirect lung injury (Table 1). Once triggered by infectious, chemical, or mechanical insult, the complex interaction between the immune system and the alveolar-capillary barrier gives rise to the pathophysiology of ALI (Lee et al. 2019). In addition, genetic studies in Chinese populations identified some genetic risk factors that might increase the development of ARDS, such as Toll-interleukin 1 receptor domain-containing adapter protein (Song et al. 2010) and the tumor necrosis factor receptorassociated factor 6 gene (Song et al. 2012). ALI is also a serious perioperative complication with crucial mortality and morbidity, and there are limited treatments available beyond conservative respiratory support (Jin et al. 2017).

Figure 1 shows the pathogenesis of ALI, including the exudative, proliferation, and fibrotic phases, and the difference between healthy and ALI alveoli (Thompson et al. 2017). The exudative phase usually takes place within $24 \mathrm{~h}$ of the

Table 1 Conditions associated with ALI

\begin{tabular}{l|l}
\hline Direct lung injury insults & Indirect lung injury insults \\
\hline Pneumonia $^{\text {a }}$ & Sepsis \\
\hline Gastric aspiration $^{\mathrm{a}}$ & Major trauma \\
\hline Pulmonary contusion & Non-cardiogenic shock \\
\hline Pulmonary embolism & Pancreatitis \\
\hline Inhalation injury & Severe burns \\
\hline Near drowning & Multiple transfusion or transfusion-associated acute lung injury \\
\hline & Cardiopulmonary bypass surgery \\
\hline & Reperfusion edema after lung transplantation or embolectomy \\
\hline & Drug overdose \\
\cline { 2 - 2 } & Genetic risk factors \\
\hline
\end{tabular}

${ }^{\text {a }}$ Pneumonia, gastric aspiration, and sepsis are the top three main triggers of ALI in recent clinical conditions 


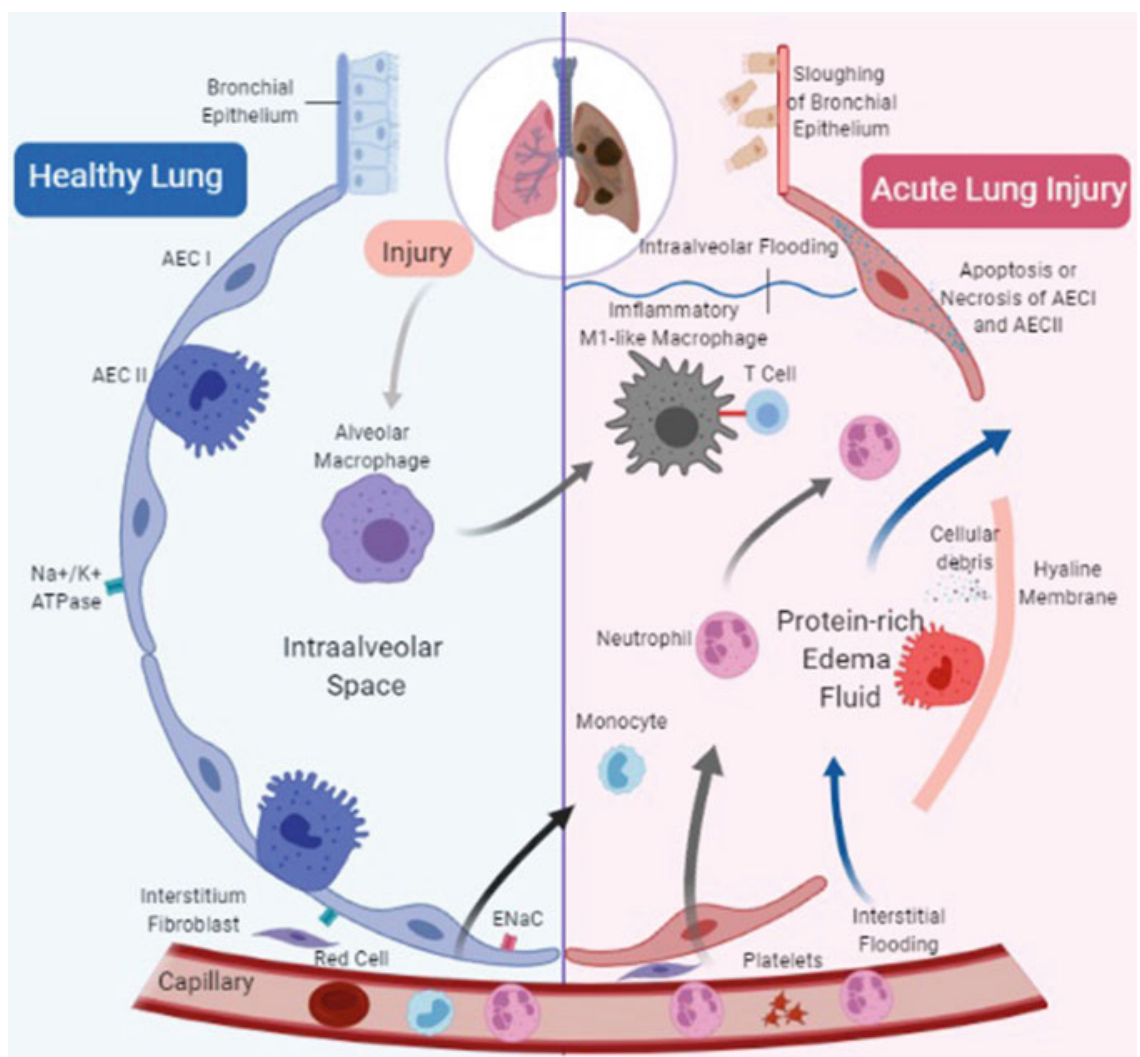

Fig. 1 The difference between a healthy and ALI alveolus. The hallmarks of ALI are disruption of alveolarcapillary barriers, recruitment of pro-inflammatory cells, formation of hyaline membranes, and flooding of proteinrich edema within the interstitium and alveolus. Injury begins with the disruption of alveolar-capillary integrity by either direct or indirect insults. Initially, resident alveolar macrophages are activated and polarized into M1-like

occurrence of insult; it is characterized by diffuse alveolar damage and represents innate cellmediated damage of the alveolar endothelial and epithelial barriers and accumulation of proteinrich edema fluid in the interstitium and alveolus. Resident alveolar macrophages (Am $\varphi$ ) recognize microbial components or tissue injury via pattern recognition receptor signaling, which leads to NFkB-dependent polarization of Am $\varphi$ into M1-like macrophages and the initiation of the exudative phase. M1-like macrophages secrete pro-inflammatory cytokines and chemokines that contribute to accumulation of neutrophils and monocytes as well as to activation of alveolar epithelial cells and effector $\mathrm{T}$ cells, which macrophages, which secrete pro-inflammatory factors that contribute to recruitment of neutrophils and monocytes to facilitate and maintain inflammation and tissue injury. Extensive damage to the alveolar epithelium directly increases the permeability of alveolar-capillary barriers, and apoptosis of AEC II weakens pulmonary surfactant secretion and alveolar fluid clearance, which aggravate protein-rich edema fluid in the interstitium and alveolus

promote and maintain inflammation and tissue injury (Aggarwal et al. 2014). Activated neutrophils contribute to lung injury by releasing pre-formed inflammatory mediators, reactive oxygen species, and proteinases and by the formation of neutrophil extracellular traps and highly injurious histones. The injured and activated endothelium and epithelium initiate tumor necrosis factor-mediated expression of tissue factor, which results in coagulation of dysregulated intra-vascular and intra-alveolar, platelet aggregation, micro-thrombi formation, and hyaline membrane formation. Extensive damage to the alveolar epithelium also leads to the loss of alveolar ion channels and weakens the 
osmotic pressure for alveolar fluid clearance, which further promotes alveolar flooding. Endothelial activation and microvascular injury further facilitate alveolar-capillary barrier disruption as well as interstitial and intra-alveolar flooding in ALI. Alveolar flooding and collapse result in severely compromised gas diffusion and hypoxemia.

Impaired and extensive epithelial injury results in the proliferative phase of ALI, which is essential for host survival and is characterized by the transient expansion of resident fibroblasts, the formation of a provisional matrix, and proliferation of airway progenitor cells and differentiation from type II alveolar epithelial cells (AEC II) to type I alveolar epithelial cells (AEC I) (Vaughan et al. 2015). In adult humans, this phase usually occurs between 3 and 7 days following respiratory failure, whereas the timing was reported to be 1 week after injury for experimental animals (Matute-Bello et al. 2011; Beasley 2010). When epithelial integrity has been rebuilt, alveolar edema is reabsorbed and alveolar architecture and function are restored.

The final fibrotic phase does not occur in all ALI patients, but evidence suggests that this phase is related to prolonged mechanical ventilation and increased mortality. Patients in this phase are substantially related to the demand of mechanical ventilation, the development of interstitial and intra-alveolar fibrosis results from extensive basement membrane damage and inadequate or delayed re-epithelialization.

\subsection{The Status of ALI Treatment}

Lung disease research has shown that ALI is a syndrome characterized by substantial heterogeneity (Thompson et al. 2017). The complex pathophysiology of ALI seems to provide a wide range of targets that offer numerous therapeutic options, but to date there is no available pharmacotherapy based on the pathophysiology of ALI. Currently, ALI treatment is limited to primarily supportive care approaches, such as lungprotective ventilation (Beitler et al. 2016), the fluid conservative strategy (National Heart and
B.I.A.R.D.S.C.T. Network 2006), and prone positioning (Fan et al. 2017). Unfortunately, supportive therapies for ARDS focus only on preventing further lung injury rather than actively accelerating tissue repair, and this is why the treatment effectiveness is so limited. In addition, current evidence from practice and research indicates that there is no safe tidal volume or airway pressure for ALI patients. Because the aerated lung volume decreases during the course of the disease, even normal tidal volumes delivered with airway pressure may induce regional overstretch, leading to further epithelium activation or injury and inflammation amplification. For patients who suffer from moderate-to-severe ARDS, ventilation while in the prone position is closely associated with decreased mortality, and this is currently recommended in clinical practice (Fan et al. 2017). Unfortunately, no pharmacologic therapy has been shown to decrease ARDS either short-term or long-term mortality. Therefore, new approaches to develop feasible therapies for ALI are needed.

\section{Animal Models to Study ALI}

\subsection{Experimental Animal Models of ALI}

Animal studies provide an experimental scenario that allows investigators to study underlying pathophysiological mechanisms and search for therapeutic approaches before translating them into humans. A good animal model should share similar anatomy and responses with humans so that it can be used to predict the feasibility of a therapeutic approach and provide a bridge from bench to bedside. However, no animal model can perfectly duplicate all human features when exposed to stimuli or treatments, and the ALI animal model is no exception. As recommended in the official documents of the American Thoracic Society (ATS), at least three of four main features of ALI should be present in an ALI animal model, including histological evidence of tissue injury, alteration of the alveolar capillary barrier, inflammatory response, and physiological 
dysfunction, which are specifically described in Table 2 (Matute-Bello et al. 2011). ATS documents also indicate that it is not necessary to establish a fully developed ALI animal model. In this regard, we previously summarized cellular mechanisms underlying lung regeneration and repair, and analyzed the role of stem cells both in small and large animal models (Yahaya 2012).

\subsection{Evaluation of Common ALI Animal Models}

For preclinical studies, numerous methods to develop animal models for ALI have been reported, including endotoxin (Wang et al. 2018; Zhu et al. 2017; Tang et al. 2017), bacteria (Monsel et al. 2015), ventilator (Hayes et al. 2015; Islam et al. 2019), and cecal ligation and puncture (Wang et al. 2015; Condor et al. 2016). According to these studies, neutrophils play an important role in the inflammatory response in ALI development in animal models, both for small and large animal.

Most ruminants, including goats and sheep, have segmented lungs, which means that many macrophages circulate in pulmonary vessels and that their pulmonary circulation tends to be sensitive to intravenous injection with endotoxin. Several studies reported that small doses of endotoxin induced increased pulmonary hypertension in these animals, and previous studies showed that smoke inhalation injury (Lange et al. 2012; Rehberg et al. 2013; Halim et al. 2019) and brushing injury (Yahaya et al. 2011; Kardia et al. 2018). Infiltration and accumulation of neutrophils were also reported to be the major feature in large animal models for ALI (Lange et al. 2012), but large animals are prone to microbial infection, so intravascular macrophages in these animals are easily augmented via stimulation of the local inflammatory reaction in response to microbe invasion.

In contrast, smaller animals and humans have fewer intravascular macrophages. Compared with large animals, small animals such as mice, rats, and rabbits are widely bred and very economical in terms of expenses. Numerous studies indicated that endotoxin-induced ALI in mice resulted in prominent inflammatory cell infiltration in the alveolar spaces, including neutrophils and macrophages, as well as interstitial edema and intra-alveolar septal thickening with fibrin and collagen deposition (Chen et al. 2014; Liou et al. 2017). The rat model showed a similar pattern of ALI characteristics following exposure to toxic chemicals such as sodium nitrate and naphthalene (Uriarte et al. 2013; Zhang et al. 2016). Moreover, activated neutrophils were found to play a key role in initiating the inflammatory processes involved in the formation of hemorrhage or alveolar damage (Wang et al. 2018; Zhu et al. 2017; Zhang et al. 2018). Murine lungs rarely develop hyaline membranes following ALI (Matute-Bello et al. 2011), whereas hyaline membranes in rabbit ALI models usually appear during the early exudative phase of ALI (Cao et al. 2012), which is consistent with the features in ALI patients. Moreover, gene sequence comparison analysis demonstrated that the rabbit shared a higher homology with the human leukocyte antigen (HLA) genes than mouse and rat, thus rabbit tissue is less likely to result in immune rejection of allotransplantation (Marche et al. 1985). Therefore, rabbits are commonly used in implantation and tissue engineering studies. However, the greater availability of specific reagents and genetically modified mice and rats make them popular for animal models.

The official ATS workshop report recommends the features and measurements of experimental ALI animal models and also describes the difference between ALI patients and several common ALI animal models in detail (Matute-Bello et al. 2011). Given the high frequency of use, we briefly summarized LPS, ventilator, and live bacteria-induced lung injury in Table 2. Almost all of the "very relevant" criteria are present in the top three most common animal models, so they can be used to further investigate the more efficient therapeutic approaches to treating ALI. The LPS-induced ALI mouse model is commonly used as a model of human ALI associated with severe pneumonia or sepsis because of its high efficiency. Intratracheal (i.t.) and intravenous (i.v.) delivery are commonly 
Table 2 Presence of "very relevant" criteria in the top three common animal models of ALI

\begin{tabular}{|c|c|c|c|c|c|c|}
\hline \multicolumn{2}{|l|}{ Human patient } & Measurement & Notes & LPS & VILI & $\begin{array}{l}\text { Live } \\
\text { bacteria }\end{array}$ \\
\hline \multirow[t]{5}{*}{$\begin{array}{l}\text { Histological } \\
\text { evidence of } \\
\text { tissue injury }\end{array}$} & $\begin{array}{l}\text { Accumulation of } \\
\text { neutrophils in the } \\
\text { alveolar/interstitial space }\end{array}$ & \multirow[t]{5}{*}{ H\&E staining } & \multirow[t]{5}{*}{$\begin{array}{l}\text { Hyaline membranes are } \\
\text { rarely observed in } \\
\text { murine models }\end{array}$} & + & + & + \\
\hline & $\begin{array}{l}\text { Formation of hyaline } \\
\text { membranes }\end{array}$ & & & + & + & + \\
\hline & $\begin{array}{l}\text { Proteinaceous debris in } \\
\text { alveolar space }\end{array}$ & & & + & + & + \\
\hline & $\begin{array}{l}\text { Thickening of the alveolar } \\
\text { wall }\end{array}$ & & & + & + & + \\
\hline & $\begin{array}{l}\text { Injury by a standardized } \\
\text { histology score }\end{array}$ & & & + & + & + \\
\hline \multirow{5}{*}{$\begin{array}{l}\text { Alteration of the } \\
\text { alveolar } \\
\text { capillary barrier }\end{array}$} & $\begin{array}{l}\text { Increased extravascular } \\
\text { lung water content }\end{array}$ & $\begin{array}{l}\text { Wet-to-dry } \\
\text { ratios }\end{array}$ & $\begin{array}{l}\text { More errors for very } \\
\text { small lungs }\end{array}$ & + & + & + \\
\hline & $\begin{array}{l}\text { Accumulation of protein/ } \\
\text { tracer in airspaces/ } \\
\text { extravascular space }\end{array}$ & EBD & $\begin{array}{l}\text { Intravenous injection in } \\
\text { advance }\end{array}$ & + & + & + \\
\hline & $\begin{array}{l}\text { Total BAL protein } \\
\text { concentration }\end{array}$ & \multirow{2}{*}{$\begin{array}{l}\text { BALF-total } \\
\text { protein } \\
\text { concentration, } \\
\text { IgM }\end{array}$} & \multirow{2}{*}{$\begin{array}{l}\text { Technical challenges } \\
\text { and difficult to } \\
\text { standardize }\end{array}$} & + & + & + \\
\hline & $\begin{array}{l}\text { BAL concentration of } \\
\text { high molecular weight } \\
\text { proteins }\end{array}$ & & & + & + & + \\
\hline & $\begin{array}{l}\text { (Micro-)vascular filtration } \\
\text { coefficient }\left(K_{\mathrm{f}}\right)\end{array}$ & $\begin{array}{l}\text { Under machine } \\
\text { testing }\end{array}$ & $\begin{array}{l}\text { Only for isolated } \\
\text { perfused lung }\end{array}$ & $(+)$ & + & $(+)$ \\
\hline \multirow[t]{3}{*}{$\begin{array}{l}\text { Inflammatory } \\
\text { response }\end{array}$} & $\begin{array}{l}\text { BAL total neutrophil } \\
\text { counts }\end{array}$ & $\begin{array}{l}\text { BALF-cytospin, } \\
\text { Wright-Giemsa } \\
\text { staining }\end{array}$ & $\begin{array}{l}\text { Neutrophil number and } \\
\text { percentage }\end{array}$ & + & + & + \\
\hline & Lung MPO activity & $\begin{array}{l}\text { ELISA kits or } \\
\text { colorimetric } \\
\text { assay }\end{array}$ & $\begin{array}{l}\text { Cell-free BALF or } \\
\text { whole lung } \\
\text { homogenates }\end{array}$ & + & + & + \\
\hline & $\begin{array}{l}\text { Concentrations of } \\
\text { cytokines }\end{array}$ & $\begin{array}{l}\text { qRT-PCR or } \\
\text { ELISA kits }\end{array}$ & $\begin{array}{l}\text { mRNA or protein } \\
\text { expression }\end{array}$ & + & $(+)$ & + \\
\hline \multirow{2}{*}{$\begin{array}{l}\text { Physiological } \\
\text { dysfunction }\end{array}$} & Hypoxemia & \multirow{2}{*}{$\begin{array}{l}\text { Under machine } \\
\text { testing }\end{array}$} & \multirow[t]{2}{*}{ Equipment limits } & + & + & + \\
\hline & $\begin{array}{l}\text { Increased alveolar-arterial } \\
\text { oxygen difference }\end{array}$ & & & + & + & + \\
\hline
\end{tabular}

Notes: $L P S$ lipopolysaccharide, VILI ventilator-induced lung injury, $B A L F$ broncho-alveolar lavage fluid, $E B D$ Evans blue dye, $M P O$ myeloperoxidase, $R T-P C R$ reverse transcriptase polymerase chain reaction, $H \& E$ Hematoxylin and eosin, ELISA enzyme-linked immunosorbent assay

+ , the criterion was present in virtually all studies using this model

$(+)$ the criterion was present in the majority of studies using this model

used to induce ALI in animal models in preclinical studies, but there are some differences between these two delivery approaches. The former is pulmonary administration, and the ALI model reveals how the alveolar epithelium structure in the lungs is injured, including by polymorphonuclear (PMN) cell infiltration in intraalveolar areas, diffuse alveolar edema, and mild changes in epithelial permeability. Use of i.v. delivery shows how the vascular endothelium structure in the lungs is injured, such as via PMN cell accumulation in capillaries and the interstitium with mild infiltration in intra-alveolar areas, presence of protein-rich alveolar edema, and mild changes in epithelial permeability. Just like in human patients, i.t. and i.v. delivery in animal models mimic direct and indirect insult, respectively. However, these animal models usually heal with few areas of fibrosis remaining, so investigators should adjust the time points in 
preclinical studies, especially in therapeutic research (Lopes-Pacheco et al. 2019).

\section{Stem Cell Therapy for ALI}

Cell therapies are new potential treatments that aim to repair injured tissue and mitigate inflammation via regeneration by virtue of their multipotency as well as the release of and regulation by their soluble bioactive factors. In recent years, preclinical studies have shown the potential of cell therapies in treating lung diseases and critical illness, and they are likely to provide novel therapeutic candidates for general ARDS patients. In this context, our group has previously established an aerosol-based cell therapy using AECs for the treatment of ALI models, both in vivo and in vitro. The results indicated that AEC delivery remarkably accelerated the repair and regeneration of the respiratory airway (Kardia et al. 2017, 2018). Currently, adult stem cells have been regarded as a promising approach for ALI because of their ability to alleviate the major pathologies underlying ALI (Zhu et al. 2013). Stem cell therapy for ALI disease is recognized as a promising option not only for controlling symptoms but also for its potential benefit as a curative treatment regimen.

\subsection{Cell Therapy Using MSCs}

To date, MSCs may offer the best choice for clinical trials due to their multi-lineage differentiation capability, potent ability to modulate the inflammation process and immune system, diverse sources, ease of harvesting, and extensive preclinical studies (Kim and Park 2017). MSCs are non-hematopoietic multipotent stem cells derived from a variety of tissues such as bone marrow, adipose tissue, umbilical cord, placenta, dental pulp of deciduous baby teeth, menstrual blood, and several organs including the liver, spleen, and lung (Samsonraj et al. 2017). In vitro functional studies indicate multiple physiological roles of MSCs related to their heterogeneity and tissue location of origin (Sacchetti et al.
2016; Klimczak and Kozlowska 2016; Heo et al. 2016). The International Society of Cellular Therapy has defined MSCs as cells having these criteria: (1) They adhere to a plastic surface under standard tissue culture conditions; (2) they express certain cell surface markers, such as CD73, CD90, and CD105, but they must not express other markers, including CD45, CD34, CD14 or CD11b, CD79a, CD19, and HLA-DR; and (3) they are able to differentiate into osteoblasts, adipocytes, and chondroblasts under standard in vitro conditions (Dominici et al. 2006). Numerous studies have demonstrated the therapeutic potential of MSCs in multiple diseases, especially for tissue injury and degenerative and immunological diseases.

Halim et al. (Halim et al. 2019) previously investigated the effects of MSC treatment on asthma-related airway inflammation via aerosolization delivery, and the results demonstrated that MSC treatment relieved airway inflammation and reversed airway remodeling. Additionally, MSCs likely are able to elude clearance by the host immune system through a variety of mechanisms, including low expression of MHC I and II proteins and lack of the T-cell costimulatory molecules, CD80 and CD86; thus, they often are referred to as being 'immuno-privileged' (Lee et al. 2011). Past studies provide a powerful basis for exploring innovative approaches for the treatment of inflammatory diseases.

Several pilot clinical trials were conducted by research institutes or hospitals from all over the world, and they can be tracked on 'clinical trial. gov' (Table 3). The aim of most of the clinical trials was to assess the safety and efficiency of MSCs in patients with ALI/ARDS. Only three early-stage clinical trials have been completed with updated results, and they demonstrated that one dose of MSCs with intravenous delivery was safe for moderate to severe ARDS patients (Zheng et al. 2014; Wilson et al. 2015; Matthay et al. 2019). However, there are multiple challenges for evaluation of treatment efficiency, as dosage, time interval, delivery route, and illness severity must be considered and compared between MSC-treated and placebo groups. Currently, the optimum therapeutic dosage of MSCs 


\begin{tabular}{|c|c|c|c|c|c|c|c|c|c|c|c|}
\hline 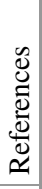 & 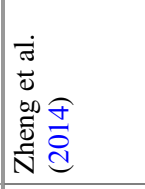 & 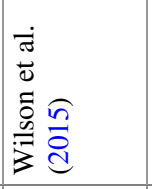 & 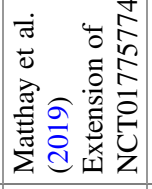 & 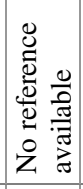 & 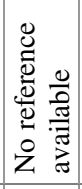 & 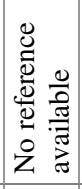 & 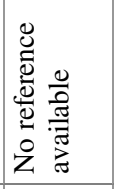 & 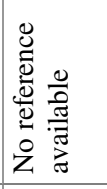 & 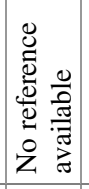 & 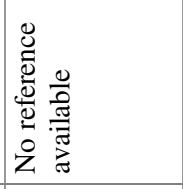 & 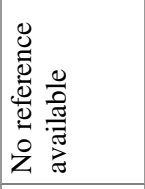 \\
\hline 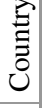 & 节 & 芯 & 芯 & 芯 & 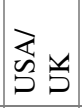 & 苞 & 节 & 节 & 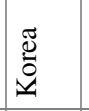 & 光 & 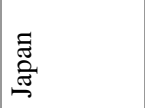 \\
\hline 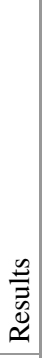 & 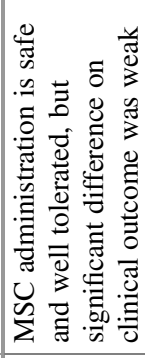 & 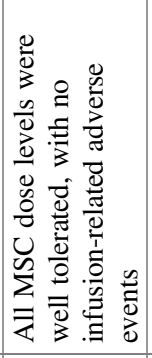 & 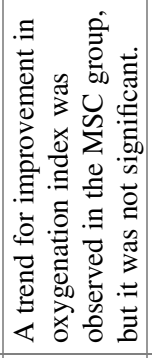 & $\begin{array}{l} \\
\\
z \\
0 \\
0 \\
0 \\
0 \\
0 \\
0 \\
0 \\
0 \\
0 \\
0 \\
z \\
z\end{array}$ & 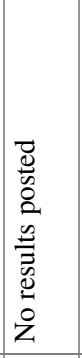 & 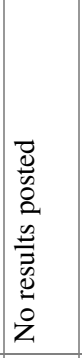 & 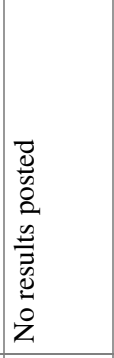 & 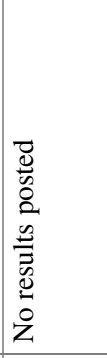 & 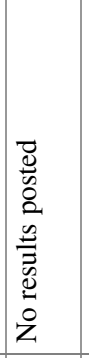 & 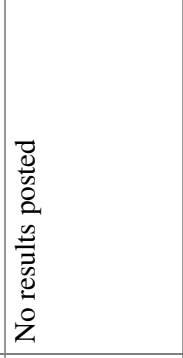 & 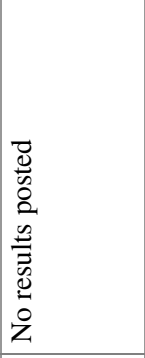 \\
\hline 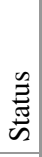 & $\begin{array}{l}\frac{0}{0} \\
\frac{0}{2} \\
\tilde{\Xi} \\
0 \\
0\end{array}$ & 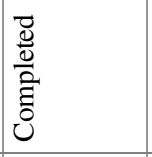 & $\begin{array}{l}\frac{\vec{d}}{\frac{0}{0}} \\
\frac{0}{2} \\
\text { Uं }\end{array}$ & $\begin{array}{l}\bar{d} \\
\frac{0}{0} \\
\frac{0}{2} \\
0 \\
0\end{array}$ & $\begin{array}{l}\frac{a}{0} \\
\frac{0}{0} \\
\frac{\vec{a}}{2} \\
0 \\
0\end{array}$ & 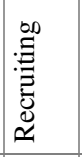 & $\begin{array}{l}5 \\
\vdots \\
0 \\
\frac{5}{5} \\
5 \\
5\end{array}$ & $\begin{array}{l}5 \\
0 \\
0 \\
\frac{5}{5} \\
5 \\
5\end{array}$ & 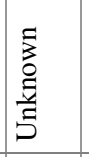 & 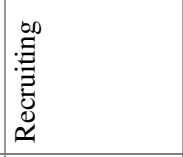 & : \\
\hline $\begin{array}{l}0 \\
\vdots \\
1 \\
0 \\
0 \\
0 \\
\end{array}$ & 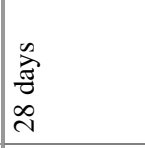 & 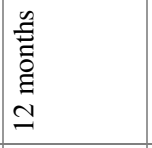 & 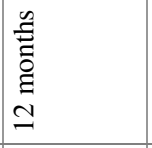 & $\begin{array}{l}\hat{\overbrace{}} \\
\hat{\overbrace{}} \\
8 \\
8\end{array}$ & 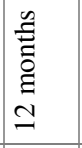 & 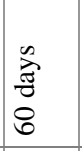 & 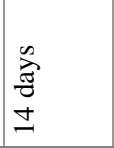 & 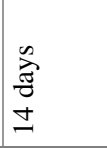 & $\begin{array}{l}\infty \\
\hat{\vec{J}} \\
\infty \\
\infty \\
\tilde{N}\end{array}$ & 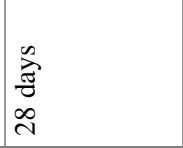 & 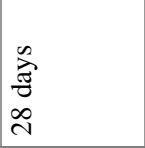 \\
\hline 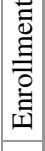 & $\begin{array}{l}0 \\
0 \\
0 \\
1 \\
\end{array}$ & $\begin{array}{c}\frac{\mathfrak{m}}{m} \\
\frac{m}{m} \\
a\end{array}$ & $\begin{array}{l}\stackrel{Ð}{1} \\
\text { o } \\
0 \\
0\end{array}$ & ¿ิ & ల) & i & ¿ิ & ¿ิ & 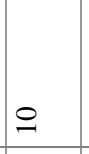 & $\stackrel{2}{\curvearrowleft}$ & ஜి \\
\hline 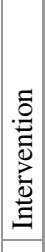 & 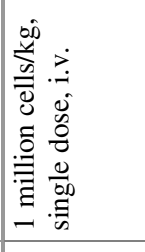 & 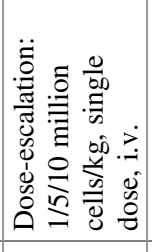 & 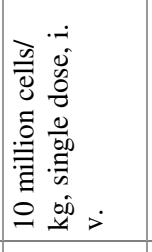 & 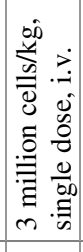 & 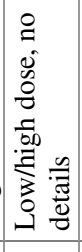 & 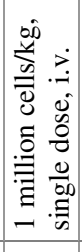 & 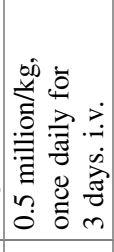 & 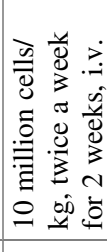 & 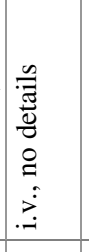 & 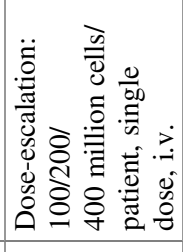 & 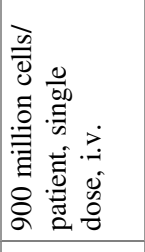 \\
\hline 莺 & 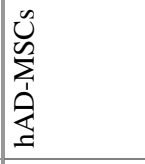 & 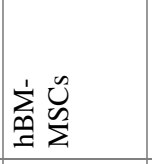 & $\sum_{\substack{1 \\
\sum_{i}^{n}}}^{n}$ & $\sum_{\substack{1 \\
\sum^{n}}}^{n}$ & 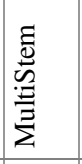 & $\begin{array}{l}\bigcup_{n}^{n} \\
\sum_{1}^{n} \\
\bigcup_{1}^{1} \\
=\end{array}$ & 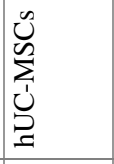 & 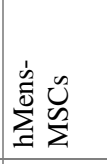 & $\sum_{\substack{1 \\
\geq}}^{n}$ & $\sum_{0}^{\infty}$ & 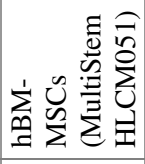 \\
\hline 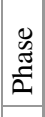 & - & - & $\stackrel{\pi}{=}$ & $=$ & $\Xi$ & 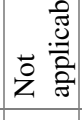 & $\Xi$ & $\Xi$ & $=$ & $\Xi$ & $=$ \\
\hline$\theta$ & 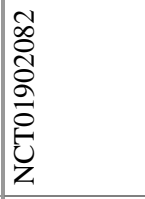 & 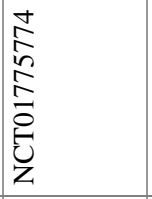 & 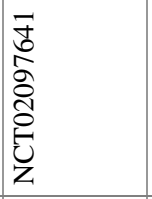 & 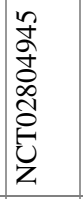 & $\begin{array}{l}8 \\
0 \\
0 \\
= \\
0 \\
1 \\
0 \\
0 \\
z\end{array}$ & $\begin{array}{l}1 \\
\alpha \\
2 \\
0 \\
0 \\
0 \\
0 \\
0 \\
z \\
z\end{array}$ & 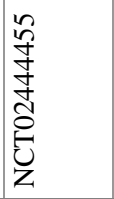 & 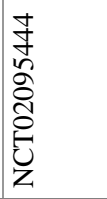 & 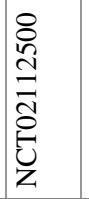 & 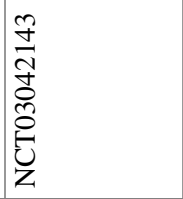 & $\begin{array}{l}4 \\
0 \\
\infty \\
\vdots \\
\infty \\
0 \\
0 \\
\qquad \\
z\end{array}$ \\
\hline$\dot{z}$ & - & N & $m$ & $\nabla$ & in & 0 & $r$ & $\infty$ & $a$ & $\varrho$ & $=$ \\
\hline
\end{tabular}




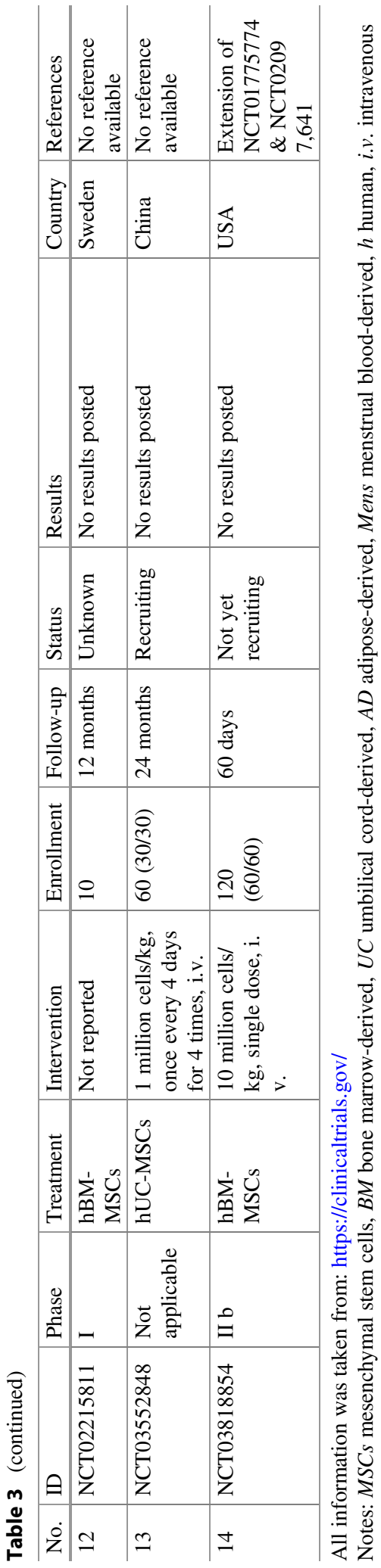


for treating lung diseases is unknown. In addition, and perhaps more importantly, we do not know whether it is necessary to deliver multiple doses of MSCs to treat advanced ALI animal models or ARDS patients.

Although the precise therapeutic mechanisms by which MSCs alleviate ALI remain unclear, a number of important insights from recent preclinical studies have emerged (Fig. 2), and they include but are not limited to cell-to-cell interactions and secretion of soluble factors, such as growth factors, matrix proteins, cytokines and extracellular vesicles, as well as through mitochondrial transfer (Lee et al. 2019; LopesPacheco et al. 2019; Zhu et al. 2013; Abraham and Krasnodembskaya 2019). MSCs have been proven to play crucial roles in anti-inflammatory and anti-apoptotic activities, to facilitate epithelial and endothelial cell restoration, and to increase microbial and alveolar fluid clearance, resulting in the improvement of lung and distal organ injury as well as survival (Lopes-Pacheco et al.
2019; Xiang et al. 2017; Pedrazza et al. 2017; Morrison et al. 2017; Ren et al. 2018).

In support of these findings, Halim et al. (Halim et al. 2018) demonstrated that MSC-secreted proteins facilitated airway epithelial repair by stimulating the regenerative ability and endogenous reparation of lung cells, and most of proteins were extracellular proteins. In addition, MSCs have been demonstrated to alleviate LPS-induced ALI through downregulation of miR-142a-5p, which mediates autophagy of pulmonary endothelial cells by increasing Beclin-1 protein (Zhou and You 2016). Additionally, the NF- $\mathrm{BB}$, MAPK, and STAT3 signaling pathways are all thought to be involved in the effects of MSC treatment in the ALI animal model, but more studies are needed to elucidate the therapeutic mechanism. So far, our group has already explored the feasibility of cell therapy both in chronic (Halim et al. 2019) and acute lung disease (Kardia et al. 2018); the results were consistent with each other, which showed

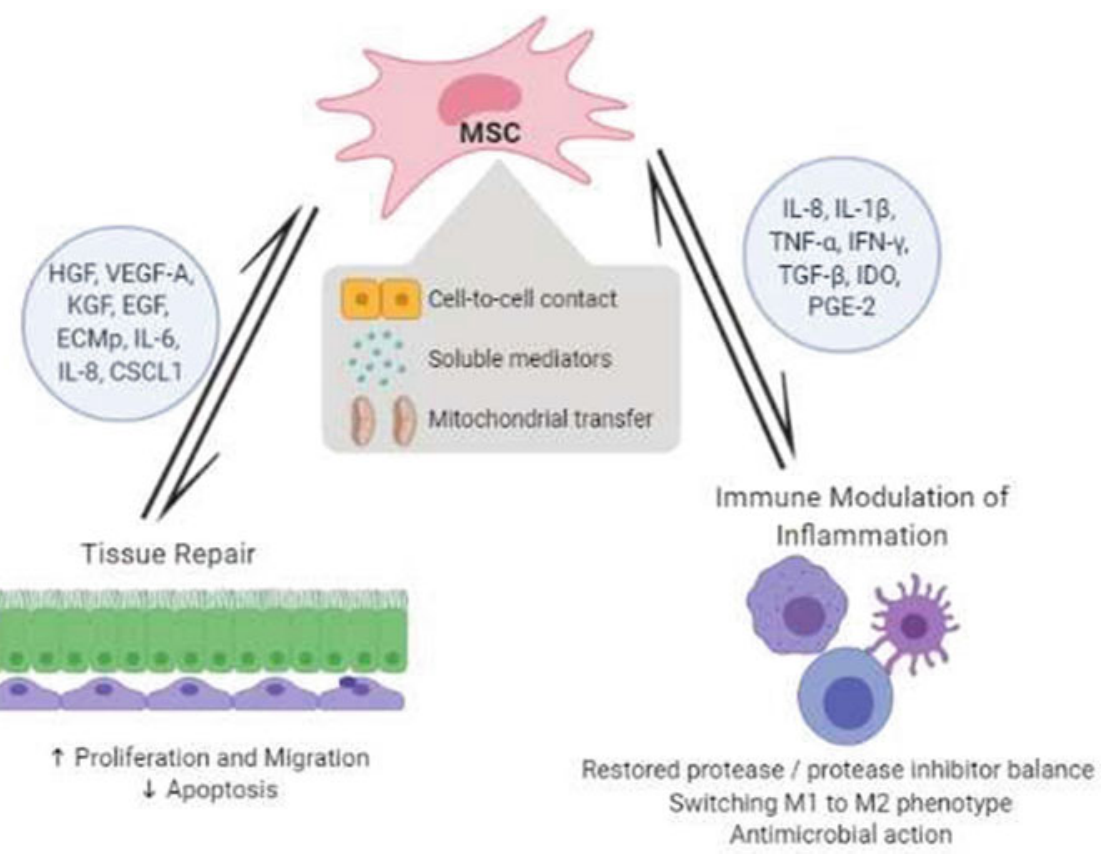

Fig. 2 Mechanisms underlying the modulation of inflammation and lung tissue repair by MSCs in ALI. MSCs have been proven to facilitate tissue repair and relieve inflammation by cell-to-cell contact, mitochondrial transfer, and paracrine or endocrine soluble factors, including growth factors, anti-inflammatory cytokines, and chemokines, as well as EVs 
that MSCs or AECs reduced inflammation of the lung and airways and facilitated lung regeneration. In summary, all of these studies provided essential knowledge and data to support the therapeutic potential of MSCs to treat ALI conditions.

Nonetheless, cell-based therapy poses the risk of occlusion in microvasculature and unregulated growth in vivo. Among these concerns, the first is the risk of tumor formation. Additionally, extensive ex-vivo expansion are required for sufficient cell numbers in clinical protocols. Controversies about the stability of human derived MSCs (hMSCs) highlight the need to address hMSC stability in long-term cultures before use in clinical treatment (Bernardo et al. 2007; Meza-Zepeda et al. 2008; Rosland et al. 2009). A numbers of studies indicated that hMSCs may contribute to cancer development and progression either by acting as cancer-initiating cells or through interactions with stromal elements (Herberts et al. 2011). Lee and Hong (2017) demonstrated that MSCs have the ability to accelerate tumor growth due to their ability to migrate and home to the tumor site and alter its microenvironment, and they also can produce cytokines that stimulate tumor growth. However, although MSCs have the ability to induce tumor growth, there is no evidence from MSC clinical trials showing the involvement of MSCs in tumor development. Further research is needed before MSCs can be considered as a safe candidate for clinical treatment in patients.

Another issue related to MSC use is dose optimization in terms of number of cells in a single dose for testing in both preclinical and clinical experiments. High doses of MSCs are associated with several safety concerns; for example, a high dose by i.v. delivery could induce pulmonary embolism. Finally, MSCs are live cells, so particular care must be taken in their storage and transportation. DMSO is required as a preservative for MSC cryopreservation, and the process of cryopreserving and thawing reduce the viability of MSCs, which could have an adverse effect on their therapeutic efficacy in patients (Matthay et al. 2019). In view of these issues, there is an urgent need to find a safer cell-free therapeutic approach. It is widely accepted that the paracrine effects of MSCs are due mainly to mediation by extracellular vesicles (EVs) secretion, so the therapeutic potential of MSC-derived EVs is being actively explored as an alternative approach to MSC-based treatments.

\subsection{MSC-EVs as a Potential Therapeutic for ALI}

Initially, the therapeutic effects of MSCs were thought to derive from their engraftment in the injury site and regeneration afterwards. However, subsequent experimental evidence demonstrated that most MSCs administered get trapped in capillary networks and are transient in injury sites, which indicates that engraftment plays little role in therapeutic action (Eggenhofer et al. 2014). Subsequent studies demonstrated that the therapeutic properties of MSCs are derived from soluble factors with paracrine or endocrine effects, including growth factors, anti-inflammatory cytokines, and antimicrobial peptides, which can facilitate alveolar epithelial proliferation and stabilize the alveolar-capillary barrier, regulate the inflammatory microenvironment, and enhance alveolar fluid clearance and decrease infection (Lee et al. 2011). These findings provided a sufficient theoretical basis for the usage of novel cellfree therapies. MSC-EVs would be one of the most compelling alternatives for cell-free therapy because of their lower risk of allogenic immune rejection, accessible preservation, and higher stability compared with MSCs. In addition, EVs can carry micro and messenger RNAs as well as lipids, proteins, and even organelles, which can be used to regulate the behavior of target cells and shift gene expression (Yáñez-Mó et al. 2015). EVs also can bypass the blood-brain barrier by transcytosis through the endothelial layers to deliver cargo biomolecules to the brain parenchyma (Chen et al. 2016). The therapeutic application of MSC-EVs remains promising, and recent studies have underlined the new potential role of EVs as a paracrine of endocrine vehicle to deliver multiple soluble factors with a similar phenotype as the parent cell (Zhu et al. 2014). 
Additionally, compared to their parent cells, EVs can be safely stored without losing function.

EVs were first clearly described by Pan and Johnstone (1983). Initially, EVs were thought to be a disposal mechanism by which cells eliminate unwanted proteins and other molecules. Subsequent research showed that EV secretions are important mediators of cell-to-cell communication that is involved in normal physiological process but also plays a crucial role in the development and progression of diseases. EVs are classified based on their cellular origin, biological function, and biogenesis, and the three main classes recognized currently are exosomes, microvesicles, and apoptotic bodies (Table 4) (El Andaloussi et al. 2013). According to the guidelines from the International Society for Extracellular Vesicles' minimal information for studies of extracellular vesicles 2018 (MISEV2018), EVs can be characterized by four distinct aspects (Théry et al. 2018). The first is quantification of EVs, both in terms of number of cell sources and the amount of EVs from a given number of cells; measurements can include the total levels of protein, lipids, or RNA. This aspect suggests that it would be informative to analyze at least one membrane bound (CD63, CD9, or CD81) and one cytosolic protein (TSG101 or ALIX) in EVs. The secondly aspect is the protein composition, specific markers in proteins, and non-protein components of EVs, and these can be analyzed using Western blotting or PCR (Hartjes et al. 2019). Third, single vesicle analysis of EVs can be conducted using visualization techniques such as transmission electron microscopy (Shao et al. 2018). Finally, other EV-associated components can be evaluated by topology analysis.

Importantly, Ratajczak et al. (2012) reported that EVs secreted by stem cells contributed to their maintenance and plasticity; in other words, stem cell-derived EVs play a critical role in tissue regeneration after injury. For example, EVs from MSCs have been used to stimulate tissue repair following cardiovascular (Lai et al. 2011), kidney (Bruno et al. 2016; Song et al. 2017) and lung (Lee et al. 2011; Hayes et al. 2012; Monsel et al. 2016) injury. On the other hand, the effect of EVs on regulation of the immune response depends on the status of particular immune cells, as they might trigger adaptive immune responses or suppress inflammation in a tolerogenic manner (Robbins and Morelli 2014). Such wide-raging cellular and biological functions indicate that MSC-EVs, in virtue of their pleiotropic signaling, may have innate therapeutic potential for regenerative medicine and immunotherapy. Moreover, Phinney et al. (2015) reported that there are functionally active mitochondria and numerous miRNAs in MSC-EVs. This is an important finding because ALI always clinically results in multiple organ dysfunction syndrome, which is

Table 4 Classification and characterization of EVs

\begin{tabular}{l|l|l|l|l}
\hline Types & Origin & Size & Content & Markers \\
\hline Exosomes & $\begin{array}{l}\text { Endolysosomal pathway; } \\
\text { intraluminal budding of } \\
\text { multivesicular bodies and } \\
\text { fusion of multivesicular } \\
\text { body with cell membrane }\end{array}$ & $40-120 \mathrm{~nm}$ & $\begin{array}{l}\text { mRNA, miRNA, and other } \\
\text { non-coding RNAs; } \\
\text { cytoplasmic and membrane } \\
\text { proteins including } \\
\text { receptors and MHC } \\
\text { molecules }\end{array}$ & $\begin{array}{l}\text { Tetraspanins } \\
\text { (TSPAN29 and } \\
\text { TSPAN30), ESCRT } \\
\text { components, } \\
\text { PDCD61P, TSG101, } \\
\text { flotillin, MFGE8 }\end{array}$ \\
\hline Microvesicles & $\begin{array}{l}\text { Cell surface; outward } \\
\text { budding of cell membrane }\end{array}$ & $50-1,000 \mathrm{~nm}$ & $\begin{array}{l}\text { mRNA, miRNA, } \\
\text { non-coding RNAs, } \\
\text { cytoplasmic proteins, and } \\
\text { membrane proteins, } \\
\text { including receptors }\end{array}$ & $\begin{array}{l}\text { Integrins, selectins, } \\
\text { CD40 ligand }\end{array}$ \\
\hline $\begin{array}{l}\text { Apoptotic } \\
\text { bodies }\end{array}$ & $\begin{array}{l}\text { Cell surface; outward } \\
\text { blebbing of apoptotic cell } \\
\text { membrane }\end{array}$ & $500-2000 \mathrm{~nm}$ & $\begin{array}{l}\text { Nuclear fractions, cell } \\
\text { organelles }\end{array}$ & $\begin{array}{l}\text { Extensive amounts of } \\
\text { phosphatidylserine }\end{array}$ \\
\hline
\end{tabular}

Notes: ESCRT endosomal sorting complex required for transport, MFGE8 milk fat globule-EGF factor 8 protein, PDCD61P programmed cell death 6 interacting protein (also known as ALIX), TSG101 tumor susceptibility gene 101 protein, TSPAN29 tetraspanin 29 
associated with mitochondrial dysfunction. Therefore, mitochondria-targeted strategies are increasingly being explored as a promising therapeutic approach for treating lung injury, and MSC-EV-mediated mitochondria transfer is one of the most exciting among them (Agrawal and Mabalirajan 2015).

Although preclinical studies of the therapeutic use of MSCs-EVs in ALI are still in their infancy, MSCs-EVs are thought to be as powerful as their parent cells in promoting remission in ALI and other inflammatory lung disease models because they pass their cargo to recipient cells, thus facilitating the therapeutic benefits. The application potential of EVs versus intact live cells is significant because: (1) they have no iatrogenic tumor risk because of their non-self-replicating property; (2) they can be stored at $-80{ }^{\circ} \mathrm{C}$ without DMSO and without loss of biological activity; (3) they offer potential for multiple doses or a higher single dose without significantly affecting the patient's hemodynamic or respiratory variables; and (4) they do not express MHC antigens so they can be used for allogeneic transplantation. However, utilization of MSC-EVs will require large-scale production and standardization, which pose issues concerning identification, characterization, and quantification.

\subsection{Routes of Cell Delivery and Their Therapeutic Impacts}

The therapeutic benefits of MSCs for ALI summarized all relevant articles from 2007 to 2019 for both natural and modified/ preconditioned MSCs, and it demonstrated that many ALI models involved LPS by i.t. and i.v. challenge (Lopes-Pacheco et al. 2019). The preclinical studies of MSCs in ALI used various delivery approaches (systemic or local), diverse doses, multiple origins (bone marrow, umbilical cord, menstrual blood, adipose, or other tissues), and different schedules of administration (before or after challenge). However, bone marrow and umbilical cord are the more common sources of MSCs, and umbilical cord-derived MSCs are currently most popular for clinical application due to their accessibility and lack of ethical concerns (Li et al. 2012; Sun et al. 2011).

Several studies demonstrated the therapeutic efficacy and mechanism of action of human MSCs in a mouse ALI model induced by i.t. administration of LPS; i.v. delivery at $4 \mathrm{~h}$ (Zhang et al. 2018; He et al. 2015; Xu et al. 2018; Liu et al. 2018) and $6 \mathrm{~h}$ (Ren et al. 2018) after LPS challenge; or i.t. delivery at $4 \mathrm{~h}$ postLPS challenge (Wang et al. 2018; Ionescu et al. 2012). In these studies, MSCs reduced alveolar inflammation and edema by decreasing the influx of inflammatory cells and total protein levels in the endotoxin-damaged alveolus. In addition, the therapeutic effects of the MSCs were comparable regardless of route of administration. Zhu et al. (2014) used the endotoxin-induced ALI mouse model to explore the therapeutic potential of MSC-EVs in ALI and reported that MSC-EVs decreased the influx of total inflammatory cells into the lung by $36 \%$ and the influx of neutrophils by $73 \%$. Similarly, in another mouse model of hypoxia-induced pulmonary hypertension, i.v. injection of MSCs-EVs resulted in delayed pulmonary influx of macrophages and reduced production of pro-inflammatory mediators compared to injection of mouse lung fibroblastderived EVs (Lee et al. 2012).

MSC administration has been performed via either systemic or local routes in experimental models. Systemic administration (e.g., i.v.) is readily available in clinical practice and provides wide distribution throughout the whole body, but it also results in cell waste along the route. In contrast, local administration (e.g., i.t.) delivers cells to the lung directly, so this is the more straightforward route for treating lung disease. However, i.t. intubation is a more difficult technique, especially for small animals such as mice and rats, whereas the i.v. route is more easily accessible for animals. Although the pulmonary first-pass effect has been detected with i.v. administration (Fischer et al. 2009), which results from cell retention in the lung, this effect may be beneficial for lung repair. 


\section{$4 \quad$ Conclusions}

In conclusion, ALI remains a severe clinical condition with high morbidity and mortality, both for adults and children, but no effective pharmacotherapy exists. However, MSC-EV therapy is likely to provide a promising option not only for controlling symptoms but also for its potential benefit as a curative treatment regimen. EVs can be readily isolated from MSCs from various sources, and MSC-EVs have shown prominent therapeutic benefits in a range of ALI animal models. MSC-EVs also are considered to be non-immunogenic and break through the bloodbrain barrier, so the therapeutic potency of MSC-EVs may be even better compared with their parental cells.

However, the dose, route, and time points of MSC-EV treatments vary substantially based on different preclinical animal studies, and the optimal treatment remains to be determined. Among the various delivery routes, intratracheal instillation seems to be the most straightforward approach to enhancing bacteria clearance, but for practical reasons it may not be feasible to instill MSCs or MSC-EVs for ALI patients (e.g., those who are hypoxemic). Thus, we need to balance efficiency and utility. Intratracheal intubation is the key technique for the pulmonaryinduced ALI animal model, and it must be verified before real animal experiments begin. Moreover, many issues need to be addressed before translation of MSC-EVs to clinical trials, including the standardization of MSC-EVs collection, appropriate assessments for MSC-EVs in ALI, and whether we need to extract one or two components from EVs. Nevertheless, MSC-EVs have great therapeutic potential for treating ALI, and this cell-free therapy should be studied further.

Acknowledgements This study was supported by the Universiti Sains Malaysia Research University Grant Scheme (1001/CIPPT/8012203) and the Fundamental Research Grant Scheme of the Ministry of Education, Malaysia (203/CIPPT/6711725). The authors declare that there is no potential conflict of interest.

\section{References}

Abraham A, Krasnodembskaya A (2019) Mesenchymal stem cell-derived extracellular vesicles for the treatment of acute respiratory distress syndrome: concise review. Stem Cells Transl Med. https://doi.org/10. 1002/sctm.19-0205

Aggarwal NR, King LS, D'Alessio FR (2014) Diverse macrophage populations mediate acute lung inflammation and resolution. Am J Physiol Lung Cell Mol Physiol 306(8):L709-L725. https://doi.org/10.1152/ ajplung.00341.2013

Agrawal A, Mabalirajan U (2015) Rejuvenating cellular respiration for optimizing respiratory function: targeting mitochondria. Am J Phys Lung Cell Mol Phys 310(2):L103-L113

Ashbaugh DG et al (1967) Acute respiratory distress in adults. Lancet 2(7511):319-323. https://doi.org/10. 1016/s0140-6736(67)90168-7

Beasley MB (2010) The pathologist's approach to acute lung injury. Arch Pathol Lab Med 134(5):719-727. https://doi.org/10.1043/1543-2165-134.5.719

Beitler JR, Malhotra A, Thompson BT (2016) Ventilatorinduced lung injury. Clin Chest Med 37(4):633-646

Bellani G et al (2016) Epidemiology, patterns of care, and mortality for patients with acute respiratory distress syndrome in intensive care units in 50 countries. JAMA 315(8):788-800

Bernard GR et al (1994) The American-European Consensus Conference on ARDS. Definitions, mechanisms, relevant outcomes, and clinical trial coordination. Am J Respir Crit Care Med 149(3):818-824

Bernardo ME et al (2007) Human bone marrow-derived mesenchymal stem cells do not undergo transformation after long-term in vitro culture and do not exhibit telomere maintenance mechanisms. Cancer Res 67 (19):9142-9149

Biehl M et al (2015) Six-month quality-of-life and functional status of acute respiratory distress syndrome survivors compared to patients at risk: a populationbased study. Crit Care 19:356. https://doi.org/10.1186/ s13054-015-1062-y

Bruno S, Porta S, Bussolati B (2016) Extracellular vesicles in renal tissue damage and regeneration. Eur $\mathrm{J}$ Pharmacol 790:83-91

Cao JP et al (2012) Autologous transplantation of peripheral blood-derived circulating endothelial progenitor cells attenuates endotoxin-induced acute lung injury in rabbits by direct endothelial repair and indirect immunomodulation. Anesthesiology 116 (6):1278-1287. https://doi.org/10.1097/ALN. Ob013e3182567f84

Chen L et al (2014) Protective effect of p-cymene on lipopolysaccharide-induced acute lung injury in mice. Inflammation 37(2):358-364

Chen CC et al (2016) Elucidation of exosome migration across the blood-brain barrier model in vitro. Cell Mol 
Bioeng 9(4):509-529. https://doi.org/10.1007/s12195016-0458-3

Condor JM et al (2016) Treatment with human Wharton's jelly-derived mesenchymal stem cells attenuates sepsis-induced kidney injury, liver injury, and endothelial dysfunction. Stem Cells Transl Med 5 (8):1048-1057. https://doi.org/10.5966/sctm.20150138

Dominici M et al (2006) Minimal criteria for defining multipotent mesenchymal stromal cells. The International Society for Cellular Therapy position statement. Cytotherapy 8(4):315-317. https://doi.org/10.1080/ 14653240600855905

Eggenhofer E et al (2014) The life and fate of mesenchymal stem cells. Front Immunol 5:148. https://doi.org/ 10.3389/fimmu.2014.00148

El Andaloussi S et al (2013) Extracellular vesicles: biology and emerging therapeutic opportunities. Nat Rev Drug Discov 12(5):347-357. https://doi.org/10.1038/ $\operatorname{nrd} 3978$

Fan E et al (2017) An official American Thoracic Society/European Society of Intensive Care Medicine/Society of Critical Care Medicine clinical practice guideline: mechanical ventilation in adult patients with acute respiratory distress syndrome. Am J Respir Crit Care Med 195(9):1253-1263

Ferguson ND et al (2012) The Berlin definition of ARDS: an expanded rationale, justification, and supplementary material. Intensive Care Med 38(10):1573-1582

Fischer UM et al (2009) Pulmonary passage is a major obstacle for intravenous stem cell delivery: the pulmonary first-pass effect. Stem Cells Dev 18(5):683-692. https://doi.org/10.1089/scd.2008.0253

Force ADT, Ranieri V, Rubenfeld G (2012) Acute respiratory distress syndrome. JAMA 307(23):2526-2533

Halim NS, Aizat WM, Yahaya BH (2018) The effect of mesenchymal stem cell-secreted factors on airway epithelial repair. Regen Med 14(1):15-31

Halim N et al (2019) Aerosolised mesenchymal stem cells expressing angiopoietin-1 enhances airway repair. Stem Cell Rev Rep 15(1):112-125

Hartjes TA et al (2019) Extracellular vesicle quantification and characterization: common methods and emerging approaches. Bioengineering 6(7). https://doi.org/10. 3390/bioengineering6010007

Hayes M et al (2012) Clinical review: stem cell therapies for acute lung injury/acute respiratory distress syndrome-hope or hype? Crit Care 16(2):205

Hayes M et al (2015) Mesenchymal stromal cells are more effective than the MSC secretome in diminishing injury and enhancing recovery following ventilatorinduced lung injury. Intensive Care Med Exp 3(1):29

$\mathrm{He} \mathrm{H}$ et al (2015) Mesenchymal stem cells overexpressing angiotensin-converting enzyme 2 rescue lipopolysaccharide-induced lung injury. Cell Transplant 24(9):1699-1715

Heo JS et al (2016) Comparison of molecular profiles of human mesenchymal stem cells derived from bone marrow, umbilical cord blood, placenta and adipose tissue. Int J Mol Med 37(1):115-125. https://doi.org/ 10.3892/ijmm.2015.2413

Herberts CA, Kwa MS, Hermsen HP (2011) Risk factors in the development of stem cell therapy. J Transl Med 9:29. https://doi.org/10.1186/1479-5876-9-29

Herridge MS et al (2016) Recovery and outcomes after the acute respiratory distress syndrome (ARDS) in patients and their family caregivers. Intensive Care Med 42 (5):725-738

Ionescu L et al (2012) Stem cell conditioned medium improves acute lung injury in mice: in vivo evidence for stem cell paracrine action. Am J Physiol Lung Cell Mol Physiol 303(11):L967-L977. https://doi.org/10. 1152/ajplung.00144.2011

Islam D et al (2019) Identification and modulation of microenvironment is crucial for effective mesenchymal stromal cell therapy in acute lung injury. Am J Respir Crit Care Med 199(10):1214-1224

Jin Z, Chun Suen K, Ma D (2017) Perioperative "remote" acute lung injury: recent update. J Biomed Res 31 (3):197-212. 20160053

Kardia E, Mohamed R, Yahaya BH (2017) Stimulatory secretions of airway epithelial cells accelerate early repair of tracheal epithelium. Sci Rep 7(1):11732

Kardia E, Ch'ng E, Yahaya B (2018) Aerosol-based airway epithelial cell delivery improves airway regeneration and repair. J Tissue Eng Regen Med 12(2):e995e1007

Khemani RG et al (2019) Paediatric acute respiratory distress syndrome incidence and epidemiology (PARDIE): an international, observational study. Lancet Respir Med 7(2):115-128. https://doi.org/10.1016/ S2213-2600(18)30344-8

Kim HJ, Park JS (2017) Usage of human mesenchymal stem cells in cell-based therapy: advantages and disadvantages. Dev Reprod 21(1):1-10. https://doi. org/10.12717/DR.2017.21.1.001

Klimczak A, Kozlowska U (2016) Mesenchymal stromal cells and tissue-specific progenitor cells: their role in tissue homeostasis. Stem Cells Int. https://doi.org/10. 1155/2016/4285215

Lai RC, Chen TS, Lim SK (2011) Mesenchymal stem cell exosome: a novel stem cell-based therapy for cardiovascular disease. Regen Med 6(4):481-492

Lange $M$ et al (2012) Time profile of oxidative stress and neutrophil activation in ovine acute lung injury and sepsis. Shock 37(5):468-472. https://doi.org/10.1097/ SHK.0b013e31824b1793

Lee HY, Hong IS (2017) Double-edged sword of mesenchymal stem cells: cancer-promoting versus therapeutic potential. Cancer Sci 108(10):1939-1946

Lee JW et al (2011) Concise review: mesenchymal stem cells for acute lung injury: role of paracrine soluble factors. Stem Cells 29(6):913-919. https://doi.org/10. 1002/stem.643

Lee C et al (2012) Exosomes mediate the cytoprotective action of mesenchymal stromal cells on hypoxiainduced pulmonary hypertension. Circulation 126 
(22):2601-2611. CIRCULATIONAHA.112.114173

Lee JH, Park J, Lee JW (2019) Therapeutic use of mesenchymal stem cell-derived extracellular vesicles in acute lung injury. Transfusion 59(S1):876-883

Li J et al (2012) Human umbilical cord mesenchymal stem cells reduce systemic inflammation and attenuate LPS-induced acute lung injury in rats. J Inflamm (Lond) 9(1):33. https://doi.org/10.1186/1476-92559-33

Liou C-J et al (2017) Water extract of Helminthostachys zeylanica attenuates LPS-induced acute lung injury in mice by modulating NF- $\mathrm{KB}$ and MAPK pathways. $\mathrm{J}$ Ethnopharmacol 199:30-38

Liu G et al (2018) Tracking of transplanted human umbilical cord-derived mesenchymal stem cells labeled with fluorescent probe in a mouse model of acute lung injury. Int J Mol Med 41(5):2527-2534

Lopes-Pacheco M et al (2019) Current understanding of the therapeutic benefits of mesenchymal stem cells in acute respiratory distress syndrome. Cell Biol Toxicol. https://doi.org/10.1007/s10565-019-09493-5

Marche PN et al (1985) Structure of a functional rabbit class I MHC gene: similarity to human class I genes. Immunogenetics 21(1):71-82

Matthay MA et al (2019) Treatment with allogeneic mesenchymal stromal cells for moderate to severe acute respiratory distress syndrome (START study): a randomised phase 2a safety trial. Lancet Respir Med 7(2):154-162

Matute-Bello G et al (2011) An official American Thoracic Society workshop report: features and measurements of experimental acute lung injury in animals. Am $\mathbf{J}$ Respir Cell Mol Biol 44(5):725-738. https://doi.org/ 10.1165/rcmb.2009-0210ST

Meza-Zepeda LA et al (2008) High-resolution analysis of genetic stability of human adipose tissue stem cells cultured to senescence. J Cell Mol Med 12 (2):553-563. https://doi.org/10.1111/j.1582-4934. 2007.00146.x

Monsel A et al (2015) Therapeutic effects of human mesenchymal stem cell-derived microvesicles in severe pneumonia in mice. Am J Respir Crit Care Med 192 (3):324-336. https://doi.org/10.1164/rccm.201410$1765 \mathrm{OC}$

Monsel A et al (2016) Mesenchymal stem cell derived secretome and extracellular vesicles for acute lung injury and other inflammatory lung diseases. Expert Opin Biol Ther 16(7):859-871

Morrison TJ et al (2017) Mesenchymal stromal cells modulate macrophages in clinically relevant lung injury models by extracellular vesicle mitochondrial transfer. Am J Respir Crit Care Med 196(10):1275-1286

National Heart L, B.I.A.R.D.S.C.T. Network (2006) Comparison of two fluid-management strategies in acute lung injury. N Engl J Med 354(24):2564-2575

Pan BT, Johnstone RM (1983) Fate of the transferrin receptor during maturation of sheep reticulocytes in vitro: selective externalization of the receptor. Cell
33(3):967-978. https://doi.org/10.1016/0092-8674( 83)90040-5

Pediatric Acute Lung Injury Consensus Conference Group (2015) Pediatric acute respiratory distress syndrome: consensus recommendations from the Pediatric Acute Lung Injury Consensus Conference. Pediatr Crit Care Med 16(5):428-439. https://doi.org/10.1097/PCC. 0000000000000350

Pedrazza L et al (2017) Mesenchymal stem cells improves survival in LPS-induced acute lung injury acting through inhibition of NETs formation. J Cell Physiol 232(12):3552-3564

Phinney DG et al (2015) Mesenchymal stem cells use extracellular vesicles to outsource mitophagy and shuttle microRNAs. Nat Commun 6:8472. https://doi.org/ 10.1038/ncomms9472

Ratajczak M et al (2012) Pivotal role of paracrine effects in stem cell therapies in regenerative medicine: can we translate stem cell-secreted paracrine factors and microvesicles into better therapeutic strategies? Leukemia 26(6): 1166

Rehberg S et al (2013) Antithrombin attenuates vascular leakage via inhibiting neutrophil activation in acute lung injury. Crit Care Med 41(12):e439-e446. https:// doi.org/10.1097/CCM.0b013e318298ad3a

Ren $\mathrm{H}$ et al (2018) Comparative effects of umbilical cordand menstrual blood-derived MSCs in repairing acute lung injury. Stem Cells Int 2018:7873625. https://doi. org/10.1155/2018/7873625

Robbins PD, Morelli AE (2014) Regulation of immune responses by extracellular vesicles. Nat Rev Immunol 14(3):195-208. https://doi.org/10.1038/nri3622

Rosland GV et al (2009) Long-term cultures of bone marrow-derived human mesenchymal stem cells frequently undergo spontaneous malignant transformation. Cancer Res 69(13):5331-5339. https://doi.org/ 10.1158/0008-5472.CAN-08-4630

Sacchetti B et al (2016) No identical "mesenchymal stem cells" at different times and sites: human committed progenitors of distinct origin and differentiation potential are incorporated as adventitial cells in microvessels. Stem Cell Rep 6(6):897-913

Samsonraj RM et al (2017) Concise review: multifaceted characterization of human mesenchymal stem cells for use in regenerative medicine. Stem Cells Transl Med 6 (12):2173-2185

Shao H et al (2018) New technologies for analysis of extracellular vesicles. Chem Rev 118(4):1917-1950

Song Z et al (2010) Genetic variants in the TIRAP gene are associated with increased risk of sepsis-associated acute lung injury. BMC Med Genet 11(168). https:// doi.org/10.1186/1471-2350-11-168

Song Z et al (2012) Genetic variation in the TNF receptorassociated factor 6 gene is associated with susceptibility to sepsis-induced acute lung injury. J Transl Med 10 (1): 166

Song Y et al (2014) Acute respiratory distress syndrome: emerging research in China. Am J Respir Crit Care Med 190(10):1090-1093 
Song Y et al (2017) Exosomal miR-146a contributes to the enhanced therapeutic efficacy of interleukin-1 $\beta$-primed mesenchymal stem cells against Sepsis. Stem Cells 35 (5): 1208-1221

Sun J et al (2011) Intrapulmonary delivery of human umbilical cord mesenchymal stem cells attenuates acute lung injury by expanding CD4+ CD25+ Forkhead Boxp3 (FOXP3)+ regulatory $\mathrm{T}$ cells and balancing anti-and pro-inflammatory factors. Cell Physiol Biochem 27(5):587-596

Tang XD et al (2017) Mesenchymal stem cell microvesicles attenuate acute lung injury in mice partly mediated by Ang-1 mRNA. Stem Cells 35 (7):1849-1859

Théry C et al (2018) Minimal information for studies of extracellular vesicles 2018 (MISEV2018): a position statement of the International Society for Extracellular Vesicles and update of the MISEV2014 guidelines. J Extracell Vesicles 7(1):1535750. https://doi.org/10. 1080/20013078.2018.1535750

Thompson BT, Chambers RC, Liu KD (2017) Acute respiratory distress syndrome. N Engl J Med 377 (6):562-572. https://doi.org/10.1056/NEJMra1608077

Uriarte SM et al (2013) Inhibition of neutrophil exocytosis ameliorates acute lung injury in rats. Shock 39 (3):286-292. https://doi.org/10.1097/SHK. $0 \mathrm{~b} 013 \mathrm{e} 318282 \mathrm{c} 9 \mathrm{a} 1$

Vaughan AE et al (2015) Lineage-negative progenitors mobilize to regenerate lung epithelium after major injury. Nature 517(7536):621-625. https://doi.org/10. 1038/nature 14112

Villar J, Blanco J, Kacmarek RM (2016) Current incidence and outcome of the acute respiratory distress syndrome. Curr Opin Crit Care 22(1):1-6

Wang Y et al (2015) Non-cultured dermal-derived mesenchymal cells attenuate sepsis induced by cecal ligation and puncture in mice. Sci Rep 5:16973. https://doi.org/ $10.1038 /$ srep 16973

Wang C et al (2018) Interleukin-10-overexpressing mesenchymal stromal cells induce a series of regulatory effects in the inflammatory system and promote the survival of endotoxin-induced acute lung injury in mice model. DNA Cell Biol 37(1):53-61. https://doi. org/10.1089/dna.2017.3735

Wilson JG et al (2015) Mesenchymal stem (stromal) cells for treatment of ARDS: a phase 1 clinical trial. Lancet Respir Med 3(1):24-32

Xiang B et al (2017) Transplantation of menstrual bloodderived mesenchymal stem cells promotes the repair of
LPS-induced acute lung injury. Int J Mol Sci 18(4). https://doi.org/10.3390/ijms18040689

Xu XP et al (2018) Genetic modification of mesenchymal stem cells overexpressing angiotensin II type 2 receptor increases cell migration to injured lung in LPS-induced acute lung injury mice. Stem Cells Transl Med 7 (10):721-730. https://doi.org/10.1002/sctm.17-0279

Yahaya B (2012) Understanding cellular mechanisms underlying airway epithelial repair: selecting the most appropriate animal models. Sci World J 2012. https:// doi.org/10.1100/2012/961684

Yahaya B et al (2011) Analysis of airway epithelial regeneration and repair following endobronchial brush biopsy in sheep. Exp Lung Res 37(9):519-535. https://doi.org/10.3109/01902148.2011.605513

Yáñez-Mó M et al (2015) Biological properties of extracellular vesicles and their physiological functions. J Extracell Vesicles 4(1):27066. https://doi.org/10. 3402/jev.v4.27066

Zhang Y et al (2016) Discovery of new MD2 inhibitor from chalcone derivatives with anti-inflammatory effects in LPS-induced acute lung injury. Sci Rep 6 (1). https://doi.org/10.1038/srep25130

Zhang S et al (2018) Nrf2 transfection enhances the efficacy of human amniotic mesenchymal stem cells to repair lung injury induced by lipopolysaccharide. J Cell Biochem 119(2):1627-1636

Zheng G et al (2014) Treatment of acute respiratory distress syndrome with allogeneic adipose-derived mesenchymal stem cells: a randomized, placebo-controlled pilot study. Respir Res 15(1):39

Zhou Z, You Z (2016) Mesenchymal stem cells alleviate LPS-induced acute lung injury in mice by MiR-142a$5 \mathrm{p}$-controlled pulmonary endothelial cell autophagy. Cell Physiol Biochem 38(1):258-266

Zhu YG et al (2013) Adult stem cells for acute lung injury: remaining questions and concerns. Respirology 18 (5):744-756

Zhu YG et al (2014) Human mesenchymal stem cell microvesicles for treatment of Escherichia coli endotoxin-induced acute lung injury in mice. Stem Cells 32(1):116-125. https://doi.org/10.1002/stem. 1504

Zhu H et al (2017) Therapeutic effects of human umbilical cord-derived mesenchymal stem cells in acute lung injury mice. Sci Rep 7:39889. https://doi.org/10. 1038/srep39889 